Original Article

\title{
Simple-measured leg muscle strength and the prevalence of diabetes among Japanese males: a cross-sectional analysis of data from the Kameda health study
}

\author{
Rumi Miyamoto, $\mathrm{MS}^{1)^{*}}$, Susumu S. Sawada, PhD ${ }^{2)}$, Yuko Gando, $\mathrm{PhD}^{3)}$, \\ Munehiro Matsushita, PhD ${ }^{4)}$, Ryoko Kawakami, PhD ${ }^{2)}$, Shingo Muranaga, PhD $^{5}$, \\ Yumiko Osawa, MS ${ }^{1)}$, KaOri Ishit, $\mathrm{PhD}^{2)}$, Koichiro OKa, $\mathrm{PhD}^{2)}$ \\ 1) Kameda Institute of Sports Science and Medicine, Kameda Medical Center: \\ 1344 Higashicho Kamogawa City, Chiba 296-0041, Japan \\ 2) Faculty of Sport Sciences, Waseda University, Japan \\ 3) Department of Physical Activity Research, National Institutes of Biomedical Innovation, \\ Health and Nutrition, Japan \\ 4) Department of Physical Recreation, School of Physical Education, Tokai University, Japan \\ 5) Kameda Rehabilitation Administration Department, Kameda Medical Center, Japan
}

\begin{abstract}
Purpose] The aim of this study was to investigate the relationship between leg muscle strength, measured by a very simple one-leg stand-up test, and the prevalence of diabetes among Japanese males to raise awareness of diabetes prevention. [Participants and Methods] This cross-sectional analysis was conducted in 1,800 Japanese males (median [interquartile range] age, 61 [56-67] years) who completed health examinations and a one-leg stand-up test. The prevalence of diabetes was defined if any of the following conditions applied: 1) fasting blood glucose level more than $126 \mathrm{mg} / \mathrm{dl}, 2)$ two-hour blood glucose level more than $200 \mathrm{mg} / \mathrm{dl}$ (75-g oral glucose tolerance test), 3) HbAlc more than $6.5 \%$, 4) diagnosed with diabetes by a physician, and/or 5) treated for diabetes. [Results] There were 490 participants with diabetes, and 517 participants were unable to complete the sit-to-stand task. When males, who could stand up, were used as a reference, the odds ratio for the prevalence of diabetes was significantly higher among those who were unable to stand up on neither leg than those who successfully stood up on both right and left legs after adjustment for covariates. [Conclusion] Low leg muscle strength, as measured by the one-leg stand-up test, was associated with a higher prevalence of diabetes among Japanese males. Because of its simplicity, this test could be useful detecting individuals who are at increased risk of developing diabetes.

Key words: One-leg stand-up test, Muscle strength, Diabetes
\end{abstract}

(This article was submitted Jun. 12, 2019, and was accepted Oct. 17, 2019)

\section{INTRODUCTION}

The International Diabetes Federation reported in 2017 that the number of diabetes is 425 million, which is one in eleven adults ${ }^{1)}$. The number is growing each year, estimated to reach 629 million by $2045^{1)}$. The same can be said about Japan. According to the survey in 2016 by the Ministry of Health, Labour and Welfare, those who are highly suspected to have diabetes were estimated to be around 10 million, the number has been rising since $1997^{2)}$. Therefore, diabetes is considered to be a major public health problem.

*Corresponding author. Rumi Miyamoto (E-mail: miyamoto1105@gmail.com)

(C2020 The Society of Physical Therapy Science. Published by IPEC Inc.

(c) (1) $\odot$ This is an open-access article distributed under the terms of the Creative Commons Attribution Non-Commercial No Derivatives

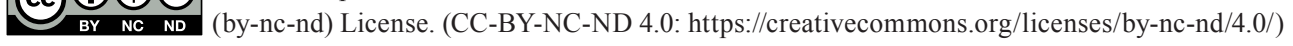


Previous studies have revealed the negative dose-response relationship between muscle strength and diabetes, and muscle strength and insulin resistance ${ }^{3-8)}$. In previous studies, grip strength has been used as a method to measure muscle strength. One of the reasons is that grip strength is easier and less costly to measure compared to measuring muscle strength of the lower limbs. This is because grip strength is known to show a correlation with the total muscle mass including the trunk and lower limbs ${ }^{9}$. On this point, however, some studies affirm the relationship between diabetes and grip strength ${ }^{5-7)}$, while others deny it ${ }^{10-12)}$. The causes include the possibility that the size of muscle groups be measured by grip strength is not large enough in carbohydrate metabolism. In addition, it has become clear that an age-related decline in muscle mass and muscle strength is more significant in lower limbs than upper limbs ${ }^{13-15)}$. As the muscle group of lower limbs controls the activities of daily living such as walking, sitting, and getting up, the decline in muscle mass and muscle strength of the area can lead to the decline in the activities of daily living along with overall physical activity. Hence, for the investigation of diabetes prevention, the relationship between diabetes and lower limbs muscle strength should be assessed.

One of the typical methods to measure lower limb muscle strength is to use an isokinetic muscle strength measuring instrument. While this method is highly appreciated for its accuracy, it requires costly and large equipment, which is restricted by space for installation, and would not be suitable for studies on a large number of participants. A hand-held dynamometer is more convenient than an isokinetic muscle strength measuring instrument, but still complicated compared to a grip strength test and requires the participant to practice. Easier ways that work for any researcher without complicated equipment, the methods using a chair such as the 30 -second stand-up test ${ }^{16,17)}$ and 5 -time stand-up test ${ }^{18)}$ are well known. Both are excellent methods, confirmed to show reliable and valid measurement results. Meanwhile, the 30-second stand-up test takes 30 seconds to measure and can be difficult for participants with decreased muscle endurance. It has also been pointed out that the 5-time stand-up test has a ceiling effect in young participants.

The solution is to use one method, which assesses the participants' quadriceps strength by having them stand up on one or both legs once from four seats of different heights - 40,30,20, and $10 \mathrm{~cm}^{19,20)}$. This test has been proven to show a positive correlation with the Weight Bearing Index that expresses participants' isometric knee extension muscle strength of their quadriceps in ratio to their weight ${ }^{19)}$. In previous studies, a reliability investigation of the stand-up test was conducted on 777 people ( $\mathrm{r}=0.73$ ), which confirmed the test to be highly reliable ${ }^{21)}$. It is one of the Locomotive Syndrome Risk Tests (Locomotest) devised by the Japanese Orthopaedic Association ${ }^{19,20)}$. This test is easy to conduct without large equipment and space, and provides an objective assessment of one's locomotive syndrome risk level through a daily living activity, standing up from a chair or box. Furthermore, the result of this test is determined by just one attempt, which makes it easy for the general population to understand their own result and can also be an effective tool to raise awareness of diabetes prevention. However, there has been neither longitudinal nor cross-sectional researches on the relationship between the stand-up test and diabetes. Therefore, in this study, we conducted a cross-sectional study to investigate the relationship between the prevalence of diabetes and the results of simple measurement of muscle strength of the lower limbs using the one-leg stand-up test.

\section{PARTICIPANTS AND METHODS}

As the Kameda Health Study is a cohort study aimed at investigating medical disorders and locomotive functions of examinee in a comprehensive medical examination (Ningen Dock) by performing musculoskeletal medical examination for examinee in a comprehensive medical examination at the Kameda Medical Center. This is a cross-sectional study using a part of this Kameda Health Study. The candidates for participants of this study were 6,383 males who underwent a two-day course of comprehensive medical examination at Kameda Medical Center during the period between September 1, 2011 and July 30 2018. The participants were chosen from 2,701 people requesting the Locomo-test as an option, who were then narrowed down to 1,803 people who underwent this test for the first time. Those who did not undergo the stand-up test, one of the items of the Locomo-test, $(n=3)$ were excluded. Ultimately, 1,800 males [median (inter quartile range) age 61 (56-67) years] who completed the entire the Locomo-test were enrolled as participants in this study. Since female participants were less than half of males, we did not conduct the research on them. This study does not use invasive approach, intervention, or samples acquired from human body, so we did not gain written or oral consensus from the participants. Instead, we released the information on this study (opt-out notice) via the website of the hospital in advance to provide the participants with an opportunity to refuse to be a participant of the study. This study was approved by the ethics committee of the Kameda Medical Center (No.17-3-190406).

The Stand-up test evaluates leg muscle strength by having them stand up on one or both legs once from four seats of different height $-40,30,20$, and $10 \mathrm{~cm}^{19,20}$. The participants are instructed to stand from each seat in descending height order, first with both legs then with one leg, without momentum and must maintain the posture for three seconds. The lowest height that they succeed is their result. The Japanese Orthopaedic Association considered those who were unable to stand up on one leg from the $40 \mathrm{~cm}$ seat as Locomo Level 1 (the risk level of locomotive syndrome). A $40 \mathrm{~cm}$ seat is almost the same height as ordinary chairs and has broad utility. In this study, we evaluated the participants based on whether they could stand up on one leg from the $40 \mathrm{~cm}$ seat on a scale of three: Succeed to stand up on both right and left legs; Fail to stand up on either the right or left leg; Fail to stand up on both right and left legs.

Body height and weight were measured using a total body composition analyzer with automatic height rod, with participants removing their shoes. Body mass index was calculated by dividing weight $(\mathrm{kg})$ by height squared $\left(\mathrm{m}^{2}\right)$. Resting 
blood pressure was measured using an H55 (Terumo Corporation, Tokyo) medical electronic sphygmomanometer. A blood chemistry test was performed using the participant's blood plasma collected after a more than 12 hour-fast. The examination items included triglyceride, and HDL-cholesterol. Furthermore, $75 \mathrm{~g}$ OGTT was conducted to measure fasting blood glucose before loading, 30 min post loading, one- hour post loading, and two- hours post loading. In addition, a self-completed questionnaire was used to investigate the participant's smoking habit, drinking habit, and physical activity, as well as their past medical history of diabetes and, if any, current treatment. Participants answered the smoking habit question with a yes or no. The definition of "yes (smoker)" are those who have smoked more than 100 cigarettes in total or over six months since they started smoking until now (as of the time of answering this question) and have been smoking in the recent month. Drinking habit was evaluated on a scale of three: Every day; Occasionally; Rarely/None. Then, the amount of alcohol intake per day was confirmed on a scale of four: Sake intake less than $180 \mathrm{ml} ; 180$ to less than $360 \mathrm{ml} ; 360$ to less than $540 \mathrm{ml}$; over $540 \mathrm{ml}$. For example, sake intake of $180 \mathrm{ml}$ is equivalent to a bottle of beer $(500 \mathrm{ml})$, Shochu $(80 \mathrm{ml}$ of 35 percent alcohol), a glass of whiskey double $(60 \mathrm{ml})$, or two glasses of wine $(240 \mathrm{ml})$. Ultimately, the participants were divided into three categories: Non-drinker group (those who drink occasionally, rarely, or none); Moderate drinker group (those who drink every day, less than $540 \mathrm{ml}$ ); Heavy drinker group (those who drink every day, over $540 \mathrm{ml}$ ). In order to assess their level of physical activity, we asked questions about their regular exercise and daily activities. As for regular exercise, we asked whether they do light exercise for over 30 minutes at a time (more than two days per week, over a year) and participants answered it with a yes or no. As for daily activities, we asked whether they walk or do physically equivalent activities in their daily life (more than an hour per day) and participants answered it with a yes or no. Ultimately, the participants were divided into three categories: Active group (those who answered yes to both questions); Moderately active group (those who answered yes to either question); Inactive group (those who answered no to both questions).

We judged the participants as having diabetes if they meet at least one of the following criteria: fasting blood glucose $126 \mathrm{mg} / \mathrm{dl}$ and above; two-hour blood glucose $200 \mathrm{mg} / \mathrm{dl}$ (75g OGTT) and above; HbA1c 6.5\% and above in NGSP ${ }^{22}$. In addition, those who answered in a self-completed questionnaire that they have been diagnosed with diabetes and those who have been treated for diabetes, were considered as having diabetes.

Firstly, as descriptive statistics, continuous variables were expressed as median and interquartile range, or as mean and standard deviation. Categorical variables were expressed as percentages (\%).

Secondly, the participants were divided into three categories based on the result of the one-leg stand-up test from a $40 \mathrm{~cm}$ seat; those who succeeded to stand up on both right and left legs; those who failed to stand up on the either right or left leg; those who failed to stand up on both right and left legs. In order to evaluate the relationship between the result of the one-leg stand-up test and prevalence of diabetes, we used a logistic regression model to calculate the age and multivariable adjusted odds ratios, as well as the $95 \%$ confidence intervals $(95 \% \mathrm{CI})$. In the logistic regression model, age was inputted as a covariate to calculate the age-adjusted odds ratios. To calculate the multivariable-adjusted odds ratios, age (continuous variable), smoking habit (non smoker or smoker), and drinking habit (non-drinker, moderate-drinker, or heavy-drinker) were inputted into the logistic regression model as covariates (Model 1). Then, physical activity habit (active, moderately active, or in-active) was added to Model 1 to calculate the multivariable-adjusted odds ratios (Model 2). As for Model 3, body mass index (continuous variable) was added to Model 2 to calculate the multivariable-adjusted odds ratios. We conducted a trend test, where we inputted the leg muscle strength of the three groups as a continuous variable into the logistic regression model to evaluate whether a linear relationship existed between leg muscle strength and the prevalence of diabetes. All statistical analyses were performed using SPSS (SPSS for Windows Ver.24, IBM, Japan). A two-tailed p-value lower than 5\% was considered statistically significant.

\section{RESULTS}

Table 1 shows the characteristics of the participants according to the results of one-leg stand-up test. The median age (interquartile range) was 61 (55-67) years old. The prevalence of diabetes was $27.2 \%$. As for the result of the one-leg standup test, the percentage of those who succeeded to stand up on both right and left legs was $71.1 \%$, those who failed to stand up on either the right or left leg was $9.9 \%$, and those who failed to stand up on both right and left legs was $18.8 \%$, indicating that more than half of them were able to stand up on both legs. The group of participants who "failed to stand up on both right and left legs" were older and had higher fasting blood glucose, HbAlc, and percentage of diabetes than the other two groups of participants who "succeed to stand up on both right and left legs" and "fail to stand up on either the right or left leg".

Table 2 shows the odds ratio of the prevalence of diabetes according to the brackets of the test results. After adjustment for age, smoking habit, and drinking habit (Model 1), the odds ratio for the prevalence of diabetes was significantly higher (1.52 $[95 \% \mathrm{CI}, 1.16-2.00]$ ) and the correlation was statistically significant ( $\mathrm{p}$ for trend $=0.003$ ) in fail to stand up on both right and left legs group compared with succeed to stand up on both right and left legs group. After adjustment for Model 1 plus physical activity (Model 2), the odds ratio was significantly higher (1.51 [95\% CI, 1.15-2.00]) in fail to stand up on both right and left legs group. After further adjustment for Model 2 plus body mass index (Model 3), the odds ratio remained significantly higher (1.37 [95\% CI, 1.04-1.81]) in fail to stand up on both right and left legs group. In both Model 2 and Model 3, the correlation of the prevalence of diabetes remained statistically significant ( $\mathrm{p}$ for trend in Model 2=0.004, in Model 3=0.037). 
Table 1. Physical characteristics by the results of the one-leg stand-up test

\begin{tabular}{|c|c|c|c|c|}
\hline & All & $\begin{array}{l}\text { Succeed to stand up on } \\
\text { both right and left legs }\end{array}$ & $\begin{array}{l}\text { Fail to stand up on either } \\
\text { right or left leg }\end{array}$ & $\begin{array}{l}\text { Fail to stand up on both } \\
\text { right and left legs }\end{array}$ \\
\hline Number of participants & 1,800 & $1,283(71.1)$ & $178(9.9)$ & $339(18.8)$ \\
\hline Age (years) & $61(56-67)$ & $59(52-64)$ & $64(60-69)$ & $67(61-73)$ \\
\hline Height $(\mathrm{cm})$ & $168.1 \pm 6.1$ & $167.7 \pm 6.0$ & $169.2 \pm 6.1$ & $169.0 \pm 6.3$ \\
\hline Body weight (kg) & $69.4 \pm 11.0$ & $68.7 \pm 10.4$ & $70.9 \pm 11.7$ & $71.2 \pm 12.6$ \\
\hline Body mass index $\left(\mathrm{kg} / \mathrm{m}^{2}\right)$ & $24.5 \pm 3.3$ & $24.4 \pm 3.1$ & $24.7 \pm 3.1$ & $24.9 \pm 3.7$ \\
\hline Waist circumference $(\mathrm{cm})$ & $86.3 \pm 8.6$ & $85.2 \pm 8.1$ & $88.1 \pm 8.5$ & $89.2 \pm 9.6$ \\
\hline Systolic blood pressure $(\mathrm{mmHg})$ & $122.5 \pm 16.5$ & $121.8 \pm 16.3$ & $124.5 \pm 15.5$ & $123.8 \pm 17.4$ \\
\hline Diastolic blood pressure (mmHg) & $77.1 \pm 11.5$ & $77.3 \pm 11.4$ & $77.4 \pm 10.9$ & $76.3 \pm 12.0$ \\
\hline Triglyceride (mg/dl) & $120.4 \pm 72.3$ & $123.2 \pm 76.7$ & $112.3 \pm 63.4$ & $113.9 \pm 56.4$ \\
\hline HDL-cholesterol (mg/dl) & $58.6 \pm 15.0$ & $58.5 \pm 15.1$ & $59.8 \pm 16.2$ & $58.2 \pm 14.0$ \\
\hline Fasting blood glucose (mg/dl) & $104.8 \pm 20.5$ & $103.3 \pm 18.3$ & $106.8 \pm 23.8$ & $109.2 \pm 25.3$ \\
\hline HbAlc (\%) & $5.8 \pm 0.7$ & $5.8 \pm 0.6$ & $5.9 \pm 0.8$ & $6.0 \pm 0.8$ \\
\hline \multicolumn{5}{|l|}{ Smoking habit, n (\%) } \\
\hline Non smoker & $1,416(78.7)$ & $1,000(77.9)$ & $139(78.1)$ & $277(81.7)$ \\
\hline Smoker & $384(21.3)$ & $283(22.1)$ & 39 (21.9) & $62(18.3)$ \\
\hline \multicolumn{5}{|l|}{ Alcohol habit, n (\%) } \\
\hline Non drinker & $1,019(56.6)$ & $731(57.0)$ & $97(54.5)$ & $191(56.3)$ \\
\hline Moderate drinker & $722(40.1)$ & $507(39.5)$ & $77(43.3)$ & $138(40.7)$ \\
\hline Heavy drinker & $59(3.3)$ & $45(3.5)$ & $4(2.2)$ & $10(2.9)$ \\
\hline \multicolumn{5}{|l|}{ Physical activity, n (\%) } \\
\hline Active & $447(24.8)$ & $297(23.1)$ & $53(29.8)$ & $97(28.6)$ \\
\hline Moderately active & $511(28.4)$ & $365(28.4)$ & $47(26.4)$ & $99(29.2)$ \\
\hline Inactive & $842(46.8)$ & $621(48.4)$ & $78(43.8)$ & $143(42.2)$ \\
\hline Prevalence of diabetes, n (\%) & $490(27.2)$ & $305(23.8)$ & $51(28.7)$ & $134(39.5)$ \\
\hline
\end{tabular}

Data are the means \pm SD or percentages. Only age is median (interquartile range).

Table 2. Odds ratios for prevalence of diabetes by the results of one-leg stand-up test

\begin{tabular}{|c|c|c|c|c|c|c|c|c|}
\hline & $\mathrm{n}$ & $\begin{array}{c}\text { Number } \\
\text { of } \\
\text { diabetes }\end{array}$ & $\begin{array}{c}\text { Number of } \\
\text { diabetes } \\
\text { (per } 1,000 \\
\text { persons) }\end{array}$ & OR $(95 \% \mathrm{CI})$ & $\begin{array}{l}\text { Age-adjusted } \\
\text { OR }(95 \% \text { CI })\end{array}$ & $\begin{array}{l}\text { Model } 1 \text { OR } \\
(95 \% \mathrm{CI})\end{array}$ & $\begin{array}{c}\text { Model } 2 \text { OR } \\
(95 \% \text { CI })\end{array}$ & $\begin{array}{l}\text { Model } 3 \text { OR } \\
(95 \% \mathrm{CI})\end{array}$ \\
\hline $\begin{array}{l}\text { Succeed to stand } \\
\text { up on both right } \\
\text { and left legs }\end{array}$ & 1,283 & 305 & 238 & 1.00 (reference) & 1.00 (reference) & 1.00 (reference) & 1.00 (reference) & 1.00 (reference) \\
\hline $\begin{array}{l}\text { Fail to stand up } \\
\text { on either right or } \\
\text { left leg }\end{array}$ & 178 & 51 & 287 & $1.29(0.91-1.83)$ & $1.06(0.74-1.51)$ & $1.05(0.74-1.51)$ & $1.06(0.74-1.51)$ & $1.00(0.70-1.43)$ \\
\hline $\begin{array}{l}\text { Fail to stand up } \\
\text { on right and left } \\
\text { legs }\end{array}$ & 339 & 134 & 295 & $2.10(1.63-2.70)$ & $1.52(1.12-2.00)$ & $1.52(1.16-2.00)$ & $1.51(1.15-2.00)$ & $1.37(1.04-1.81)$ \\
\hline $\mathrm{p}$ value for trend & & & & $\mathrm{p}<0.001$ & 0.003 & 0.004 & 0.004 & 0.037 \\
\hline
\end{tabular}

Model 1: Adjusted for age, smoking habit, and drinking habit.

Model 2: Model 1 plus physical activity.

Model 3: Model 2 plus body mass index.

CI: confidence interval; OR: odds ratio.

\section{DISCUSSION}

This study was conducted with Japanese males to examine the relationship between the prevalence of diabetes and the results of the one-leg stand-up test, which measures the participants' muscle strength of the lower limbs by whether they can stand up on one leg from a $40 \mathrm{~cm}$ seat.

The Japan National Health and Nutrition Survey 2016 reported "those who are highly suspected to have diabetes" were $16.3 \%$, while "those with a possibility to have diabetes" were $12.2 \%$, totaling $28.5 \%$ ). The prevalence of diabetes in this study was $27.2 \%$, which shows no great difference with the result of the survey. The previous study has revealed the relationship between muscle strength and diabetes ${ }^{3-8)}$. Momma et al. followed 21,802 Japanese people aged between 20 and 92 for six years and reported that those who with weaker grip strength in relation to their weight tended to have a higher risk of developing type 2 diabetes $^{7)}$. They also followed 1,840 elderly people aged between 70 and 79 in their local community 
for three years, reporting that patients with type 2 diabetes, compared to those without type 2 diabetes, showed decreased lower limb muscle mass and knee extension muscle strength ${ }^{3)}$. The stand-up test has been proven to have an association with quadriceps strength ${ }^{19)}$, as the action of standing up can only be achieved when a total value of knee joint and hip joint muscle strength is maintained at a certain level ${ }^{23)}$. This test, therefore, is a method to comprehensively measure overall muscle strength of the lower limbs around the quadriceps. The results of this study also confirmed the relationship between muscle strength of the lower limbs and diabetes through conducting a one-leg stand-up test with Japanese males, supporting the previous study. Many studies have also reported the relationship between physical activities and diabetes ${ }^{24,25)}$. A large scale epidemiological study with 70,000 clinical nurses showed that regular light exercise can lower the risk of developing type 2 diabetes $^{25}$. In this study, we adjusted for the risk factors of diabetes, including age, smoking, drinking, and obesity, as well as physical activities. The results showed, even after adjustment for physical activities, those who are unable to clear a one-leg stand-up test had a higher prevalence of diabetes.

Skeletal muscles are a main organ to metabolize sugars. The contraction of skeletal muscles moves glucose transporter 4 (GLUT4) from inside the cell to the cell membrane, enhancing the uptake of sugars. A study that compared the amount of GLUT4 between patients with type 2 diabetes and without type 2 diabetes has revealed that the patients with type 2 diabetes have a significantly decreased amount of GLUT4 ${ }^{26}$. It also showed that general muscle mass of patients with type 2 diabetes are relatively low compared to patients without type 2 diabetes ${ }^{27}$. The lower limbs muscle group around the quadriceps used in the stand-up test occupies a large area of whole body, hence considered to play a large role in metabolizing sugars. Kawakami et al. reported that those who are unable to stand up on one leg from a $40 \mathrm{~cm}$ seat tended to have declined muscle strength and muscle mass ${ }^{28)}$. That's why it is considered that the muscle strength of the lower limbs evaluated in the stand-up test has an association with the prevalence of diabetes.

The characteristic of this study is having used a simple one-leg stand-up test to measure muscle strength of the lower limbs. Previous studies on the relationship between muscle strength and diabetes often used grip strength ${ }^{9}$ which is easy to measure ${ }^{5-7,10-12)}$. However, it has become clear that an age-related decline in muscle mass and muscle strength is more significant in the lower limbs than the upper limbs ${ }^{13-15}$. In addition, Nomura et al. studied the relationship between continued regular exercise of patients with type 2 diabetes and their leg extension muscle strength, elucidating the interaction between regular exercise habits and leg extension muscle strength, while pointing out that high leg extension muscle strength can yield a significant effect on regular exercise habits. Therefore, the measurement of lower limb muscle strength is a meaningful approach. Although the measurement of lower limbs muscle strength had a drawback in its complexity compared to grip strength, this study used a $40 \mathrm{~cm}$ seat, about the same height as ordinary chairs, to make the measurement easier. As the muscle group of the lower limbs controls vital lifestyle functions such as walking, sitting, and getting up, the decline in these muscle mass and muscle strength could bring significant influence for the prevention and the improvement of diabetes. In that sense, evaluating one's lower limbs muscle strength through a one-leg stand-up test is not only relevant to the prevalence of diabetes, but can also enhance exercise prescription to prevent diabetes. Also evaluating leg muscle strength through this test could be effective for the general population to raise awareness of diabetes prevention.

This study has some limitations. First, age distribution of the participants of this study are limited and it is unclear if the same results can be achieved with younger people. Secondly, all participants are males and it is unclear if the same results can be achieved with females. Lastly, due to the nature of the cross-sectional study, this study does not refer to any causal connection.

The study showed that Japanese males who are unable to clear a one-leg stand-up test tended to have a higher percentage of diabetes. The test used in this study uses a seat with the same height as ordinary chairs, which makes it easy to conduct without large equipment and space, and provides an objective assessment of one's locomotive syndrome risk level through a daily living activity. In addition, the test result is determined by just one attempt, which makes it easy for participants to understand their own result.

\section{Conflict of interest}

The authors declare that they have no conflict of interest.

\section{ACKNOWLEDGEMENTS}

We would like to express our sincere gratitude to every participant of the Locomo-test and hospital staff who were engaged in the test at Kameda Medical Center. Also, we would like to extend our deepest appreciation to the experts who have given their guidance. This work was supported by research aid from the Japanese Orthopaedic Assoication Project Research. This study, in part, was presented as a poster at 21st Congress on Japanese Association of Exercise Epidemiology, Shinjuku, Tokyo, Japan, June 23-24, 2018. http://jaee.umin.jp/doc/meeting_21_abstract.pdf) and also presented at 66th The American College of Sports Medicine Annual Meeting, Minneapolis, Minnesota, USA, May 29-June 2, 2018. 


\section{REFERENCES}

1) International Diabetes Federation: Diabetes Atlas, 2017. https://diabetesatlas.org/resources/2017-atlas.html (Accessed Feb. 25, 2019)

2) Ministry of Health, Labour and Welfare: The report of National Health and Nutrition, 2016. https:/www.mhlw.go.jp/bunya/kenkou/eiyou/dl/h28-houkoku.pdf (Accessed March 15, 2019).

3) Park SW, Goodpaster BH, Strotmeyer ES, et al.: Health, aging, and body composition study: Accelerated loss of skeletal muscle strength in older adults with type 2 diabetes: the health, aging, and body composition study. Diabetes Care, 2007, 30: 1507-1512. [Medline] [CrossRef]

4) Leenders M, Verdijk LB, van der Hoeven L, et al.: Patients with type 2 diabetes show a greater decline in muscle mass, muscle strength, and functional capacity with aging. J Am Med Dir Assoc, 2013, 14: 585-592. [Medline] [CrossRef]

5) Cuthbertson DJ, Bell JA, Ng SY, et al.: Dynapenic obesity and the risk of incident Type 2 diabetes: the English longitudinal study of ageing. Diabet Med, 2016, 33: 1052-1059. [Medline] [CrossRef]

6) Li JJ, Wittert GA, Vincent A, et al.: Muscle grip strength predicts incident type 2 diabetes: population-based cohort study. Metabolism, 2016, 65: 883-892. [Medline] [CrossRef]

7) Momma H, Sawada SS, Kato K, et al.: Physical fitness tests and type 2 diabetes among Japanese: a longitudinal study from the Niigata wellness study. J Epidemiol, 2019, 29: 139-146. [Medline] [CrossRef]

8) Nomura $\mathrm{T}$, Ishiguro $\mathrm{T}$, Ohira M, et al.: Isometric knee extension force in Japanese type 2 diabetic patients without apparent diabetic polyneuropathy: Data from the Multicenter Survey of the Isometric Lower Extremity Strength in Type 2 Diabetes study. SAGE Open Med, 2019, 7: 2050312118823412. [Medline] [CrossRef]

9) Rantanen T, Era P, Heikkinen E: Maximal isometric strength and mobility among 75-year-old men and women. Age Ageing, 1994, 23: 132-137. [Medline] [CrossRef]

10) Wander PL, Boyko EJ, Leonetti DL, et al.: Greater hand-grip strength predicts a lower risk of developing type 2 diabetes over 10 years in leaner Japanese Americans. Diabetes Res Clin Pract, 2011, 92: 261-264. [Medline] [CrossRef]

11) Leong DP, Teo KK, Rangarajan S, et al. Prospective Urban Rural Epidemiology (PURE) Study investigators: Prognostic value of grip strength: findings from the Prospective Urban Rural Epidemiology (PURE) study. Lancet, 2015, 386: 266-273. [Medline] [CrossRef]

12) Marques-Vidal P, Vollenweider P, Waeber G, et al.: Grip strength is not associated with incident type 2 diabetes mellitus in healthy adults: The CoLaus study. Diabetes Res Clin Pract, 2017, 132: 144-148. [Medline] [CrossRef]

13) Janssen I, Heymsfield SB, Wang ZM, et al.: Skeletal muscle mass and distribution in 468 men and women aged 18-88 yr. J Appl Physiol 1985, 2000 , 89: 81-88. [Medline] [CrossRef]

14) Tanimoto Y, Watanabe M, Kono R, et al.: [Aging changes in muscle mass of Japanese]. Nippon Ronen Igakkai Zasshi, 2010, 47: 52-57 (in Japanese). [Medline] [CrossRef]

15) Yamauchi J, Mishima C, Nakayama S, et al.: Aging-related differences in maximum force, unloaded velocity and power of human leg multi-joint movement. Gerontology, 2010, 56: 167-174. [Medline] [CrossRef]

16) Jones CJ, Rikli RE, Beam WC: A 30-s chair-stand test as a measure of lower body strength in community-residing older adults. Res Q Exerc Sport, 1999, 70: 113-119. [Medline] [CrossRef]

17) Nakatani T, Nadamoto M, Mimura K-I, et al.: Validation of a 30-sec chair-stand test for evaluating lower extremity muscle strength in Japanese elderly adults. Japanese journal of physical education, 2002, 47: 451-461.

18) Lord SR, Murray SM, Chapman K, et al.: Sit-to-stand performance depends on sensation, speed, balance, and psychological status in addition to strength in older people. J Gerontol A Biol Sci Med Sci, 2002, 57: M539-M543. [Medline] [CrossRef]

19) Muranaga S: Evaluation of the muscular strength of the lower extremities using the standing movement and clinical application. J Showa Med Assoc, 2001, 61: 362-367 (in Japanese).

20) Japanese Orthopaedic Association: Locomotive syndrome pamphlet 2015. Tokyo: The Locomotive Challenge! Council, 2015. https://locomo-joa.jp/en/index. pdf (Accessed Jun. 25, 2018)

21) Ogata T, Muranaga S, Ishibashi H, et al.: Development of a screening program to assess motor function in the adult population: a cross-sectional observational study. J Orthop Sci, 2015, 20: 888-895. [Medline] [CrossRef]

22) American Diabetes Association: Diagnosis and classification of diabetes mellitus. Diabetes Care, 2014, 37: S81-S90. [Medline] [CrossRef]

23) Yoshioka S, Nagano A, Himeno R, et al.: Computation of the kinematics and the minimum peak joint moments of sit-to-stand movements. Biomed Eng Online, 2007, 6: 26. [Medline] [CrossRef]

24) Helmrich SP, Ragland DR, Leung RW, et al.: Physical activity and reduced occurrence of non-insulin-dependent diabetes mellitus. N Engl J Med, 1991, 325: 147-152. [Medline] [CrossRef]

25) Hu FB, Sigal RJ, Rich-Edwards JW, et al.: Walking compared with vigorous physical activity and risk of type 2 diabetes in women: a prospective study. JAMA, 1999, 282: 1433-1439. [Medline] [CrossRef]

26) Gaster M, Staehr P, Beck-Nielsen H, et al.: GLUT4 is reduced in slow muscle fibers of type 2 diabetic patients: is insulin resistance in type 2 diabetes a slow, type 1 fiber disease? Diabetes, 2001, 50: 1324-1329. [Medline] [CrossRef]

27) Kim KS, Park KS, Kim MJ, et al.: Type 2 diabetes is associated with low muscle mass in older adults. Geriatr Gerontol Int, 2014, 14: 115-121. [Medline] [CrossRef]

28) Kawakami R, Murakami H, Gando Y, et al.: One-Leg Stand-Up Test as a simple assessment tool for predicting sarcopenia. Desanto Sport Science, 2016, 37: 92-98 (in Japanese). 